Article

\title{
Biodegradable Carbon-based Ashes/Maize Starch Composite Films for Agricultural Applications
}

\author{
Enrica Stasi ${ }^{1}$, Antonella Giuri ${ }^{2}$, Francesca Ferrari ${ }^{1}$, Vincenza Armenise ${ }^{3}{ }^{(0)}$, Silvia Colella ${ }^{4}$, \\ Andrea Listorti $2,3\left(\mathbb{D}\right.$, , Aurora Rizzo $^{2}$, Eleonora Ferraris ${ }^{5}(-)$ and Carola Esposito Corcione $1,2, *$ (i) \\ 1 Dipartimento di Ingegneria dell'Innovazione, Università del Salento, 73100 Lecce, Italy; \\ enrica.stasi@unisalento.it (E.S.); francesca.ferrari@unisalento.it (F.F.) \\ 2 Istituto di Nanotecnologia CNR-Nanotec c/o Campus Ecotekne, Via Monteroni, 73100 Lecce, Italy; \\ antonella.giuri@unisalento.it (A.G.); andrea.listorti@uniba.it (A.L.); aurora.rizzo@unisalento.it (A.R.) \\ 3 Dipartimento di Chimica, Università di Bari “A. Moro", via Orabona, 4, 70126 Bari, Italy; \\ vincenza.armenise@uniba.it \\ 4 Istituto di Nanotecnologia CNR-Nanotec c/o Dipartimento di Chimica, Università di Bari “A. Moro", \\ via Orabona, 4, 70126 Bari, Italy; silvia.colella@unisalento.it \\ 5 Department of Mechanical Engineering, Campus de Nayer, 2860 KU Leuven, Belgium; \\ eleonora.ferraris@kuleuven.be \\ * Correspondence: carola.corcione@unisalento.it
}

Received: 14 February 2020; Accepted: 26 February 2020; Published: 1 March 2020

check for updates

\begin{abstract}
The aim of this work is the development and characterization of biodegradable thermoplastic recycled carbon ashes/maize starch (TPAS) composite films for agricultural applications. A proper plasticizer, that is, glycerol, was added to a commercial maize starch in an amount of 35 wt.\%. Carbon-based ashes were produced by the biomass pyro-gasification plant CMD ECO 20, starting from lignocellulosic wastes. The ashes were added to glycerol and maize native starch at different amounts ranging from $7 \mathrm{wt} . \%$ to $21 \mathrm{wt} . \%$. The composite was mixed at $130{ }^{\circ} \mathrm{C}$ for $10 \mathrm{~min}$ and then molded. The effect of the different amounts of carbon based ashes on the thermal and physical-mechanical properties of the composite was assessed by using several techniques, such as rheology, wide-angle X-ray diffraction (WAXD), scanning electron microscopy (SEM), differential scanning calorimetry (DSC), thermogravimetric analysis (TGA), moisture absorption, degradation and mechanical tests. The presence of the carbon waste ashes allows to improve thermal and durability performances of the thermoplastic starch (TPS) films. It reduces the water absorption of starch matrix and strongly decreases the deterioration of starch, independently from fillers amount, enhancing the lifetime of the TPS films in outdoor conditions. In addition, the waste carbon ashes/maize starch films present an advantage in comparison to those of neat starch; it can biodegrade, releasing the plant nutrients contained in the ashes into the soil. In conclusion, this approach for recycling carbon waste ashes increases the efficiency of industrial waste management, along with a reduction of its impact on the environment.
\end{abstract}

Keywords: carbon based ashes; maize starch; thermoplastic films; thermo-mechanical characterization; agricultural application

\section{Introduction}

This study suggests a novel and cost-effective reutilization of carbon waste ashes as reinforcing fillers of biocomposite films, based on thermoplastic starch, for agricultural applications. To the best of our knowledge this approach was never been proposed before, especially in the field of biodegradable covers of agricultural crops, covers that are able to release nutrients into the soil. Currently, the employment of carbon-based ashes mostly includes: (i) the improvement and fertilization 
of forest and agricultural soils; (ii) the production of construction materials (such as cement and concrete); (iii) new effective adsorbents; (iv) the synthesis and production of minerals, ceramics and other materials [1]. On the other hand, several studies have been already performed on the re-use of different waste materials as fillers for thermoplastic biopolymers, such as polylactic acid (PLA), Poly(3-hydroxy-butyrate) or starch. Lactic acid (LA), which is produced by chemical conversion of corn or other carbohydrate sources into dextrose, is a biodegradable, bio-based (bio-derived) and renewable polymer. Despite being a promising biopolymer, with good mechanical properties, PLA has a higher cost of production if compared to petroleum-derived polymers. Also, another drawback lies in its high brittleness [2]; nevertheless, several studies demonstrated that natural plasticizers can be used to improve the toughness of PLA [3,4]. Poly(3-hydroxy-butyrate) (PHB) is obtained by the Alcaligens eutrophorus bacteria; as it is produced by the bacterial fermentation of renewable resources, PHB is considered one of the most interesting biodegradable polymers. Moreover, PHB shows a hydrophobic behavior and, being a linear saturated polyester, can be easily processed at relatively low temperatures, thus obtaining mechanical performances comparable to those of PP. On the other hand, PHB has the disadvantage of being thermal instable when processed to temperatures closed to the melting point, showing a relatively low impact resistance $[5,6]$. Noticeably, starch is abundant, cost effective, sustainable and biodegradable. It has a semicrystalline structure, composed of 1,4-linked $\alpha$-D-glucopyranosyl units with the two major macromolecular chains being the amylose and amylopectin [7]. The amylose is an almost linear polymer with $\alpha$-D- $(1,4)$ glycosidic linkages, while the amylopectin is a highly branched polymer which also contains $\alpha$-D- $(1,6)$ glycosidic linkages at the branching points, in addition to $\alpha$-D- $(1,4)$ glycosidic linkages [8]. Starch is one of most commonly used biopolymer in many application fields, such as in agriculture, food and pharmaceutical industries for the synthesis of films and coatings [7].

The interest in using thermoplastic starch in agricultural applications initiated in the 1970s and intensified in the 1980s, along with the dramatic growth in the utilization of plastics worldwide and the concerns on its effects on the environment. In the last years, several studies have specifically proposed the employment of thermoplastic starch-based composites as agricultural mulch films [9]. For instance, blends of starch and synthetic polymers, such as EVA and PVA, were investigated and resulted to be promising as films for paper or agricultural mulch [10]. In References [11,12], blends of starch and poly(ethylene-co-acrylic acid) were also processed into biodegradable films and earmarked as agricultural mulch or packaging material. Moreover, films composed of polybutyrate adipate terephthalate and starch were studied in Reference [13], to minimize soil temperature and humidity while increasing photosynthesis and peanut yield. In particular, the films with a starch amount of 150 g per kg presented similar results to the typically used synthetic polymer films, for the entire growing season. Furthermore, starch foils and poly(butylene adipate-co-terephthalate) blends were developed as cover films in the production of strawberries [14]. After four weeks, the ripe fruits were collected and the mean fresh weights (grams per fruit) of strawberries produced with commercial and biodegradable covering films were compared with each other and they did not vary significantly. However, after five weeks, the biodegradable film exhibited small cracks and reduced tensile strength and within 8 weeks the mechanical properties of the film were fully compromise - the weight decreased due to variations in temperature, humidity and solar radiation, which led to its biodegradation, crosslinking and photo degradation. On the contrary, in Reference [15], a biodegradable liquid, composed of oxidized maize starch and gelatin from leather residues, was utilized as coating of agricultural foils in the growth of rapeseed. The coated films demonstrated to be suitable for agricultural production and the rate of survival and yield of rapeseed increased. Finally, native and oxidized thermoplastic corn starch, with and without the addition of natural and modified bentonite (incorporating an eco-friendly natural polymer, such as chitosan) were proposed as soil cover [16]. The oxidized film evidenced higher degree of crystallinity and less plasticization than the native ones, due to the higher $T_{g}$.

However, starch is sensitive to moisture and weak in terms of mechanical property [7]. Hence, it is typically combined with a number of fillers, even waste based fillers, to produce biocomposites with 
enhanced mechanical and physical properties. As an example, Benito-González I. et al. incorporated cellulose fillers (from Posidonia waste biomass) into thermoplastic corn starch films and observed significant improvements in the mechanical and water resistance performance [17]. In Reference [18], Ibrahim M.I.J. et al. prepared biodegradable composite films by using thermoplastic corn starch as matrix and corn husk fibers (which refers to the leaves covering the corn ear) as a reinforcing filler, evidencing a noticeable reduction in density and moisture content, less resistance to biodegradation and enhanced thermal stability of the composite films. Moreover, Collazo-Bigliardi S. et al. added hydrothermal extracts and cellulose fibers, obtained from coffee and rice husks, into corn starch films, conferring to the samples antioxidant and antibacterial characteristics and improved tensile properties [19]. Furthermore, Sreekumar P.A. et al. obtained microcrystalline cellulose from olive pits (waste material from the olive industry) and used them as a filler of thermoplastic corn starch films and these fillers enhanced the tensile properties [20]. Finally, according to [21], the incorporation of chestnut husks, a lignocellulosic agroforestry waste, in thermoplastic potato starch films can increase the elastic modulus of the samples.

However, thermoplastic corn starch foils containing recycled carbon ashes have never been developed for agricultural applications. The use of recycled carbon ashes is not yet massively diffused and in a recent study an innovative reutilization of carbon-based ashes as catalysts and reinforcing filler for the crosslinking reaction of epoxy resins with amines was proposed [22,23]. It is expected, that these films in addition to covering crops have the advantage of biodegrading and releasing the plant nutrients of the ashes into the soil. The soil application of the carbon ashes, derived from the combustion of lignocellulosic biomass would ideally match the need of plants for nutrients and essential elements [1].

Therefore, this work deals with the use of carbon waste ashes as fillers of innovative biocomposite thermoplastic starch films for agricultural applications. The aim is to provide cultivation covering foils characterized by enhanced thermal and physical-mechanical properties, which can also biodegrade, meanwhile releasing the plant nutrients into the soil. Those carbon ashes are the waste of the pyro-gasification process of lignocellulosic biomass, carried out on the CMD ECO 20 plant, developed by Costruzioni Motori Diesel (CMD). Considering that those particles would be waste to be landfilled, their re-utilization would remove a considerable economic and environmental burden of the company. Hence, the here proposed recycling approach increases the efficiency of industrial waste management, along with a reduction of its negative effects on the environment.

\section{Materials and Methods}

\subsection{Materials}

The maize starch Maizena used in this work was purchased from Unilever (Rome, Italy). The glycerol was supplied by Cruciani prodotti Crual s.r.l. (Rome, Italy) and it was used as a plasticizer. The ashes were produced by the biomass pyro-gasification plant CMD ECO 20. The company Costruzioni Motori Diesel (CMD, San Nicola la Strada, Italy) developed the CMD ECO 20 system to produce heat and electric power, starting from innovative lignocellulosic waste. $100 \mathrm{~g}$ of ashes were milled for $24 \mathrm{~h}$ in an aluminous porcelain jar $(1.5 \mathrm{~L})$, using alumina balls in ambient atmosphere. The mechanical milling was performed in a horizontal oscillatory mill MMS-Ball Mill, operating at $\pm 25 \mathrm{~Hz}$.

Wide-angle X-ray diffraction (WAXD) patterns of the ashes were obtained using an automatic Bruker D2 Phaser diffractometer (Billerica, MA, USA), in reflection mode, at $35 \mathrm{KV}$ and $40 \mathrm{~mA}$, using nickel-filtered Cu-K radiation (1.5418 $\AA$ ). Thermogravimetric analysis (TGA) of the ashes was performed using a TGA TA instrument SDT Q600 (TA Instrument, New Castle, DE, USA). About $10 \mathrm{mg}$ of powder samples was heated in an alumina holder under nitrogen atmosphere from 20 to $800^{\circ} \mathrm{C}$ at a heating rate of $10^{\circ} \mathrm{C} / \mathrm{min}$. The morphology of the ashes was investigated by scanning electronic 
microscopy (SEM) using a Zeiss Scanning Electron Microscope Evo40. Energy dispersive X-ray (EDX) analysis was performed with a Bruker, XFlash detector 5010 [22,23].

\subsection{Preparation of Thermoplastic Carbon Ashes/Maize Starch Films}

The thermoplastic carbon ashes/maize starch (TPAS) films were manually prepared by pre-mixing maize starch neat powders with $35 \mathrm{wt} . \%$ of glycerol, respect to the starch matrix and recycled carbon ashes in an amount of $10 \mathrm{phr}, 20 \mathrm{phr}$ and $30 \mathrm{phr}$ that correspond to $7 \mathrm{wt} . \%, 14 \mathrm{wt} . \%$ and $21 \mathrm{wt} . \%$ [17-21] (see Figure 1). The compounds were mixed at $130{ }^{\circ} \mathrm{C}$ for $10 \mathrm{~min}$ by using a Haake PolyLab System Rheomix 600/610 mixer ( $\mathrm{n}=100 \mathrm{rpm}$ ) (Haake, Karlsruhe, Germany) and then put in a Carbolite LHT6/120 oven (Carbolite, Derbyshire, UK) until they reached a temperature of $130{ }^{\circ} \mathrm{C}$. Finally, they were compression molded, by means of a DGTS P7/91 press (DGTS, Veduggio (MB), Italy), at a pressure of 70 bar. Figure 1 reports the process parameters adopted, along with the weight composition and sample ID of each film produced.

\begin{tabular}{|c|c|c|c|}
\hline \multicolumn{2}{|c|}{$\begin{array}{c}\text { Mixing } 130^{\circ} \mathrm{C}, 10 \mathrm{~min} \\
n=100 \mathrm{rpm}\end{array}$} \\
\hline Sample ID & Maize starch (wt. \%) & Carbon ashes (wt.\%) & Glycerol (wt.\%) \\
\hline TPS & 65 & 0 & 35 \\
\hline TPAS7 & 60 & 7 & 33 \\
\hline TPAS14 & 55 & 14 & 31 \\
\hline TPAS21 & 51 & 21 & 28 \\
\hline
\end{tabular}

Figure 1. Production steps and settings of the thermoplastic starch films containing maize starch, glycerol and carbon ashes in different proportion. Weight composition of starch/carbon ashes samples.

\subsection{Rheological Characterization}

The effectiveness of glycerol as plasticizer was assessed by rheological analysis, using a TA Instrument Ares rheometer (TA Instrument, New Castle, DE, USA). Three tests were performed on starch plastisols with $35 \mathrm{wt} . \%$ of glycerol, by using a double plate geometry, setting a gap of $0.3 \mathrm{~mm}$, a constant oscillatory amplitude $(1 \%)$ and frequency $(1 \mathrm{~Hz})$, while increasing the temperature from $20{ }^{\circ} \mathrm{C}$ to $200^{\circ} \mathrm{C}$ at $3{ }^{\circ} \mathrm{C} / \mathrm{min}$. An increase of the viscosity upon heating, due to the gelation process, was considered to be indicative of the plasticizing effectiveness of the glycerol.

The effect of the different amounts of carbon-based ashes on the thermal and physical-mechanical properties of the molded thermoplastic carbon-based ashes/starch samples was assessed by using several techniques as following reported.

\subsection{Wide Angle X-ray Diffraction}

The film crystallinity was studied via WAXD analysis, on a Philips PW 1729 (Phillips, Eindhoven, the Netherlands), in reflection mode, using nickel-filtered $\mathrm{Cu}-\mathrm{K} \alpha$ radiation (1.5418 $\AA$ ). Hence, the degree of crystallinity of each film was calculated using the formula proposed by Hermans and Weidinger, as follows (Equation (1)) [24]:

$$
\% \text { Crystallinity }=\frac{Q_{s t}-Q_{a m}}{Q_{s t}} \times 100,
$$

where $Q_{s t}$ and $Q_{a m}$ are the areas calculated under the X-ray curves from the semi-crystalline and amorphous samples, respectively.

\subsection{Morphological Characterization}

A Zeiss SUPRA 40 field emission scanning electron microscope (FESEM) was utilized to investigate the morphology of composite films. Images were acquired with an Everhart-Thornley detector 
at a working distance in the range $2.5-3 \mathrm{~mm}$, electron acceleration voltage (extra-high tension, ETH) of $3.00 \mathrm{kV}$, magnification in the range 1.00-100.00 KX. Before SEM observations the samples were sputter-coated with $30 \mathrm{~nm}$ of $\mathrm{Cr}$ using a turbo-pumped sputter coater (Quorum Technologies, model Q150T).

\subsection{Differential Scanning Calorimetry}

The glass transition temperature $\left(T_{g}\right)$ and melting heat $\left(\Delta H_{m}\right)$ were estimated using a DSC, supplied by Mettler Toledo 622 (Mettler Toledo, Columbus, OH, USA). Dynamic DSC scans were performed from 20 to $250^{\circ} \mathrm{C}$, at a heating rate of $20^{\circ} \mathrm{C} / \mathrm{min}$ under nitrogen atmosphere. At least three measurements were performed on each sample. The value of the $T_{g}$ was calculated by identifying the point corresponding to the presence of an inflection (inflection point method). Thus, the $T_{g}$ coincides with the point at which the second derivative is zero.

\subsection{Thermogravimetric Analysis}

Thermogravimetric analysis is one of the most appropriate methods for the study of the thermal degradation and stability of polymeric blends as a key point of the optimization is indeed involved in the analysis of the decomposition of the material when subjected to heat increase. A first output given by the TGA curve consists in the threshold decomposition temperature, which allows identifying a process window for the polymer application. On the other hand, the threshold temperature of a polymeric blend could be not clearly identifiable if an overlapping of different phenomena, such as evaporation and degradation, occurs during the test. Therefore, in this work a study of the kinetics of the different decomposition processes was performed, in order to identify the degradation mechanism occurring during the degradation process.

In particular, the thermal stability of the films was assessed by TGA, with a TA Instrument SDT Q600 (TA Instrument, New Castle, DE, USA). The samples were heated in an alumina holder, from 20 to $700{ }^{\circ} \mathrm{C}$ at a heating rate of $10{ }^{\circ} \mathrm{C} / \mathrm{min}$ under nitrogen atmosphere; and three measurements were performed on each film.

Additionally, the kinetic analysis of the TGA results [25] was carried out in order to evaluate the difference in thermal decomposition of starch systems before and after ash addition.

Specifically, given a homogeneous system, the thermal decomposition can be expressed as:

$$
\frac{d \alpha(t)}{d t}=K(T) f[\alpha(t)],
$$

where $K(T)$ is the rate coefficient, which follows the Arrhenius equation, $\alpha(t)$ is the reaction extent of the component of the sample during degradation at a given time $t$, defined as:

$$
\alpha(t)=\frac{\left(w_{0}-w(t)\right)}{\left(w_{0}-w_{\infty}\right)}
$$

with $w_{0}, w(t)$ and $w_{\infty}$ the weight of the sample before degradation, during degradation at a certain time $t$ and after degradation, respectively.

The most commonly form for the differential conversion function, $f(\alpha(t))$ is

$$
f(\alpha(t))=(1-\alpha(t))^{n}
$$

where $n$ is the reaction order, assumed to remain constant during reaction [26].

Being $\beta$ the heating rate, defined as $\beta=d T / d t$, Equation (2) can be expressed as follows:

$$
\frac{d \alpha(t)}{(1-\alpha(t))^{n}}=\frac{A}{\beta} \exp \left(-\frac{E_{a}}{R T}\right) d T,
$$


where

- $\quad E_{a}$ is the activation energy;

- $A$ is the Arrhenius pre-exponential factor;

- $\quad R$ is the gas constant $(8.31 \mathrm{~J} / \mathrm{mol} \cdot \mathrm{K})$.

Since degradation of starch can be assumed to be of first order in sample weight reaction [27] (i.e., $\mathrm{n}=1$ ), Equation (5) can be written as:

$$
\ln (1-\alpha(t))=-\frac{A}{\beta} \int_{T_{0}}^{T} \exp \left(-\frac{E_{a}}{R T^{\prime}}\right) d T^{\prime} .
$$

Since Equation (5) cannot be integrated in an exact form, the Broido method can be applied [28]; it assumes that the temperature range of analysis is close to the melting temperature and therefore (Equation (6)) that

$$
\exp \left(-\frac{E_{a}}{R T}\right) \cong\left(\frac{T_{m}}{T}\right)^{2} \exp \left(-\frac{E_{a}}{R T}\right) .
$$

Equation (5) can be rewritten as:

$$
\ln (1-\alpha(t))=-\frac{A R T_{m}^{2}}{\beta E} \exp \left(-\frac{E_{a}}{R T}\right)
$$

or

$$
\ln \left(-\ln ((1-\alpha(t)))=-\frac{E_{a}}{R T}+C .\right.
$$

By applying this method to the TGA analysis on starch samples, a straight line will be observed between $\ln \left(-\ln ((1-\alpha(t)))\right.$ and $1 / \mathrm{T}$, with a slope of $-\frac{E_{a}}{R}$. Hence, by interpolating with a linear fit, the activation energy of the degradation process for each mixture can be calculated.

\subsection{Moisture Absorption and Biodegradation Tests}

The moisture absorption of the films was tested in a Binder KBF 115 controlled climate chamber (Binder, Tuttlingen, Germania), as a function of time at relative humidity (u.r.) of $75 \%$ and temperature of $23{ }^{\circ} \mathrm{C}$. The tests were performed on three specimens of each film of rectangular shape kept at relative humidity of $50 \%$ and temperature of $23{ }^{\circ} \mathrm{C}$, for three days long before the experiments. Each sample was periodically weighed, until a constant mass was achieved. The imbibition coefficient, $c_{i m}$, was calculated as (Equation (10)):

$$
c_{i m}=\frac{w_{t}-w_{0}}{w_{0}} \times 100,
$$

where $w_{t}$ is the mass of the samples at time, $t=48 \mathrm{~h}$ and $w_{0}$ is the mass of the samples at time, $t=0$. Biodegradation was tested on three rectangular $\left(20 \times 10 \mathrm{~mm}^{2}\right)$ specimens. The test specimens were immersed in water, in sealed vials and placed in an oven for $312 \mathrm{~h}$ at $50{ }^{\circ} \mathrm{C}$. The weight of each specimen was measured after 2, 4, 6, 24, 48, 144, 168, 192, 216 and $312 \mathrm{~h}$.

\subsection{Mechanical Characterization}

Finally, the TPAS films containing 7 wt.\% of ashes, were selected and characterized by tensile tests. The mechanical properties, such as the tensile strength, $\sigma_{\max }$, elastic modulus, $E$ and ultimate strain, $\varepsilon_{u}$, were measured at $22{ }^{\circ} \mathrm{C}$, according to the ASTM D882-97 [29] (specimen dimension-120 $\times 12 \times 0.4-0.6 \mathrm{~mm}$ ) and by using a Lloyd LR5 K dynamometer (Lloyd Instruments Ltd., Bognor Regis, West Sussex, UK). The results were then compared to those of the TPS film $(0 \%$ carbon ashes content). Five tests were performed on each film. The TPS and TPAS7 films were also 
mechanically characterized after moisture absorption, in order to assess the influence of humidity on the mechanical properties.

\section{Data Processing and Experimental Results}

\subsection{Starch and Carbon Ashes Characterization}

The structural, morphological and thermal characterization of the commercial Maizena starch was performed in a previous work [30]. The WAXD spectrum of the maize starch powder showed seven characteristic peaks and a degree of crystallinity of about $23.3 \%$. The scanning electron microscopy (SEM) analysis evidenced the presence of circular granules. The DSC analysis showed a melting point of $120^{\circ} \mathrm{C}$ and a melting heat of $41.5 \mathrm{~J} \cdot \mathrm{g}^{-1}$. Finally, the TGA curve exhibited a first degradation step from 50 to $95{ }^{\circ} \mathrm{C}$, attributed to the water loss and a second step from about 296 to $322{ }^{\circ} \mathrm{C}$, associated to the degradation of the starch [30].

The characterization of the milled ball carbon ashes was performed by WAXD and TGA in Reference [22]. The WAXD curve of the ashes (not shown here) exhibited several crystalline peaks which could be attributed to potassium chloride $(\mathrm{KCl})$, sodium chloride $(\mathrm{NaCl})$ and calcium carbonate $\left(\mathrm{CaCO}_{3}\right)$ and only one peak at $2 \theta=26.5^{\circ}$, which was related to graphite [22].

The TGA curves (reported in Figure 2a) entailed several weight losses steps due to the variety of carbon ashes composition. In details, the main steps observed are-the first step, ranging from room temperature to about $100{ }^{\circ} \mathrm{C}$, attributed to the removal of the molecularly adsorbed water, the second step between $100{ }^{\circ} \mathrm{C}$ and $250^{\circ} \mathrm{C}$, originated from the removal of the thermally labile oxygen-containing functional groups [22] and the step ranging from $600^{\circ}$ to about $700{ }^{\circ} \mathrm{C}$ due to the decomposition of $\mathrm{CaCO}_{3}$.

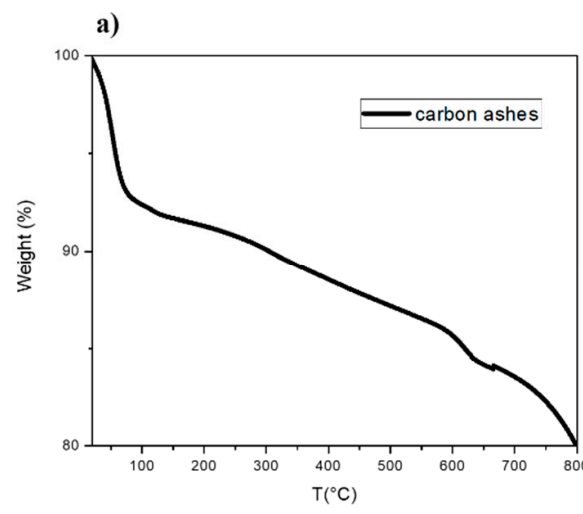

b)

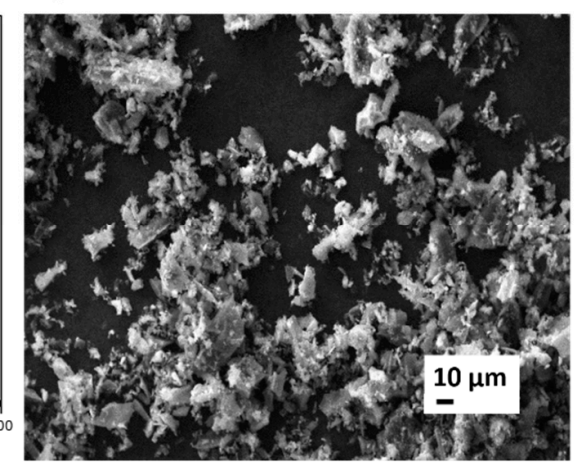

c)

\begin{tabular}{|c|c|}
\hline Element & Concentration (\%) \\
\hline $\mathbf{A l}$ & 0.19 \\
\hline $\mathbf{C}$ & 77.63 \\
\hline $\mathbf{C a}$ & 3.41 \\
\hline $\mathbf{C l}$ & 0.80 \\
\hline $\mathbf{F e}$ & 0.12 \\
\hline $\mathbf{K}$ & 2.34 \\
\hline $\mathbf{M g}$ & 0.49 \\
\hline $\mathbf{N a}$ & 0.71 \\
\hline $\mathbf{O}$ & 13.57 \\
\hline $\mathbf{P}$ & 0.14 \\
\hline $\mathbf{S}$ & 0.13 \\
\hline $\mathbf{S i}$ & 0.50 \\
\hline
\end{tabular}

Figure 2. (a) Thermogravimetric analysis (TGA); (b) Scanning electron microscopy (SEM) image and (c) chemical composition by energy dispersive X-ray (EDX) of the ashes.

The SEM image of the ashes in Figure $2 b$ reveals that the size of the fragments/particles is around $20 \mu \mathrm{m}$. The presence of $\mathrm{NaCl}, \mathrm{CaCO}_{3}$ and $\mathrm{KCl}$ was also confirmed by SEM-EDX analysis as reported in the table inserted in Figure 2c. The most abundant element is carbon, present in a percentage of about $78 \%$. The most plentiful elements, beside carbon, $(>1 \%)$ are $\mathrm{O}, \mathrm{Ca}$ and $\mathrm{K}$. The following elements are present in an amount lower than $1 \%-\mathrm{Al}, \mathrm{Cl}, \mathrm{Fe}, \mathrm{Mg}, \mathrm{Na}, \mathrm{P}$ and $\mathrm{S}$.

\subsection{Thermoplastic Carbon Ashes/Maize Starch Films Characterization}

\subsubsection{Rheology}

Rheological analyses were performed on starch plastisols mixed with $35 \mathrm{wt} . \%$ of glycerol, at room temperature (TPS film composition). Previous works were carried out with the aim of optimizing the type and the amount of plasticizer, thus leading to the conclusion that the addition of $35 \mathrm{wt} . \%$ of glycerol involves the highest plasticization yields [30]. 
The analysis of the complex viscosity during heating provides information about the evolution of the gelation process, which involves adsorption of the plasticizer by the starch powders. As observed in Figure 3, the gelation process involves a significant increase of the viscosity of the plastisol between $70{ }^{\circ} \mathrm{C}$ and $85^{\circ} \mathrm{C}$. Such increase is attributed to the swelling of the starch particles due to glycerol absorption [31] and therefore plasticization of the polymer. First, the viscosity decreases as a result of heating. The plastisol is a suspension, with the starch particles dispersed within the plasticizer. Afterwards, at a sufficiently high temperature (depending on the type of plasticizer, on the characteristics of the polymer and on the concentration of plasticizer) the plasticizer is physically absorbed by the starch particles with their consequent swelling. The particles grow in size and touch themselves, with a resulting increase in the viscosity of the compound. Finally, a second increase in viscosity occurs, due to the swelling of the starch particles with higher dimensions. The analysis of the dynamic viscosity of the component therefore provides important information regarding the process window; the viscosity curve of TPS in Figure 3 shows a final swelling temperature of $90^{\circ} \mathrm{C}$, therefore, a process temperature higher than $90^{\circ} \mathrm{C}$ must be chosen in order to ensure a complete swelling of the material during the mixing phase.

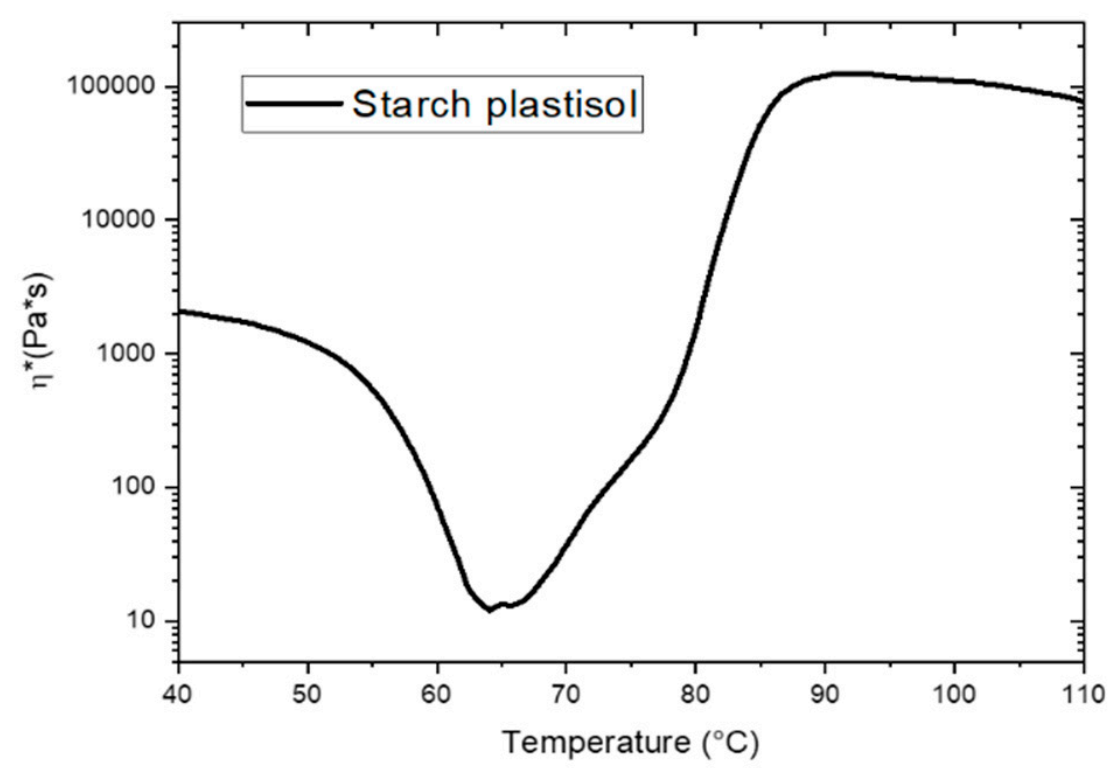

Figure 3. Rheological analysis on starch plastisol with 35 wt.\% of glycerol.

The mixing temperature was chosen also taking into account the melting temperature of starch; as shown in Figure 6a, TPAS melting starts at $125^{\circ} \mathrm{C}$, therefore, processing starch and glycerol at $130^{\circ} \mathrm{C}$ allows a partial melting of the components and improves their mixing.

Since the plasticization involves only the polymer and is not affected by the presence of the ashes, the same swelling conditions were found for every amount of carbon ashes added to the plastisol.

\subsubsection{Morphology}

In order to analyze the crystalline structure of the TPAS films, those were characterized by XRD analysis and the results were compared to that of the thermoplastic maize starch film (TPS).

The results confirm the semi-crystalline nature of all starch films, both in presence than in absence of ashes (Figure 4a). In particular, all the prepared TPAS samples show a first peak at $2 \theta=12.7^{\circ}$, a second peak at $2 \theta=17.0^{\circ}$, a third one at $2 \theta=19.8^{\circ}$ and the last one at $2 \theta=22.2^{\circ}$ (Figure $4 \mathrm{~b}$ ). The findings are comparable to the literature data on the thermoplastic starch films [32]. Therefore, the presence of the filler does not influence the crystal planes of the starch, as all the peaks appear at the same $2 \theta$ angles. 


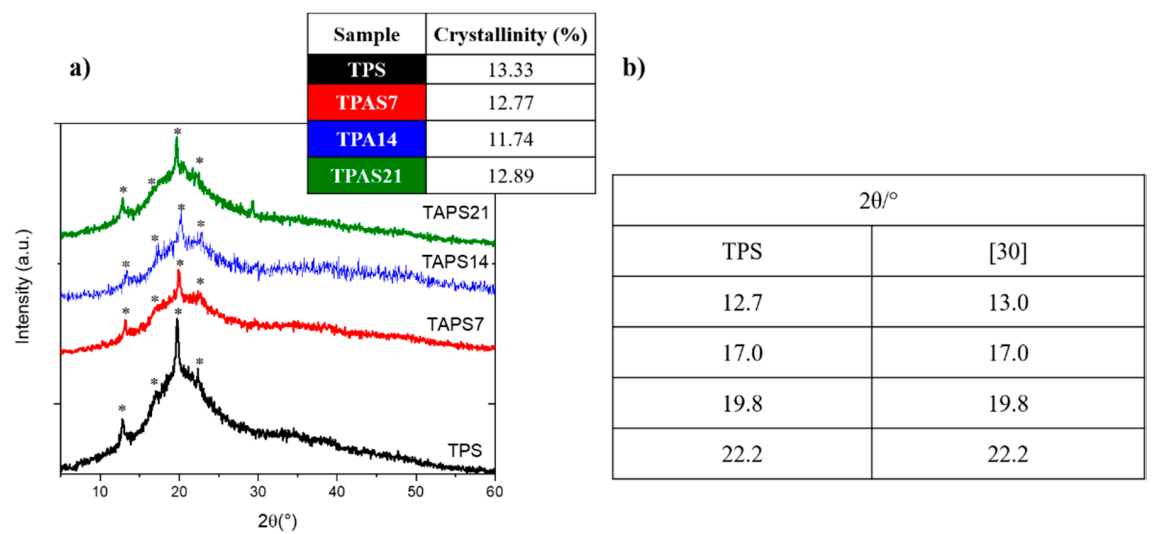

Figure 4. (a) X-ray diffraction (XRD) spectra of the thermoplastic recycled carbon ashes/starch (TPAS) films compared to that of the thermoplastic maize starch film and crystallinity values in the insert; (b) characteristic peaks of the TPAS films obtained by XRD curves compared to the literature data [30] on thermoplastic starch films [32].

The XRD diffraction patterns of all samples were used to estimate the degree of crystallinity, as the ratio between the area of the peaks and the total area of the XRD pattern, including the amorphous halo band (Equation (1)). Results, reported in the insert of Figure 4a, indicate that the filler amount does not affect the crystallinity of starch, since the same crystalline fraction is present in $7 \mathrm{wt} . \%$ and $21 \mathrm{wt} . \% \mathrm{c}$ ashes embedding films.

Representative SEM images of TPS and TPAS films are shown in Figure 5. The low-magnification images demonstrate the presence of increasing ashes concentration between TPAS7 and TPAS21 films. Particularly, a good carbon ashes dispersion can be observed for TPAS7, while an inhomogeneous distribution with the formation of aggregates and clusters is observed in TPAS14 and, especially, in TPAS21 as evidenced by high-magnification SEM images.

a)

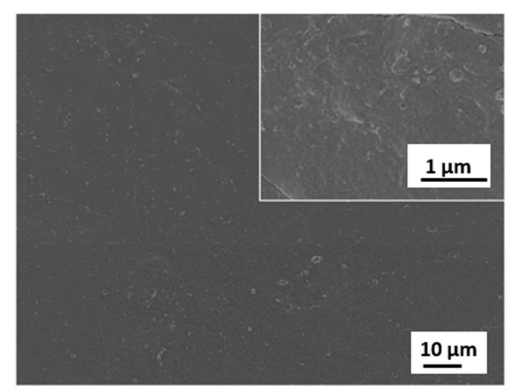

c)

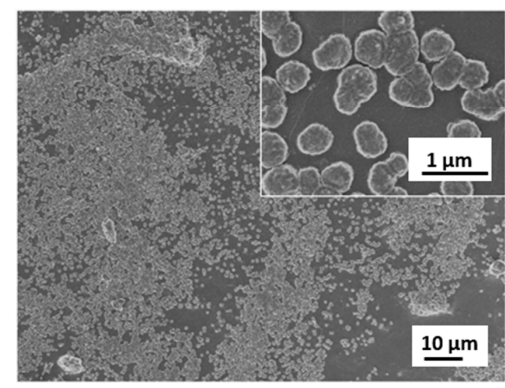

b)

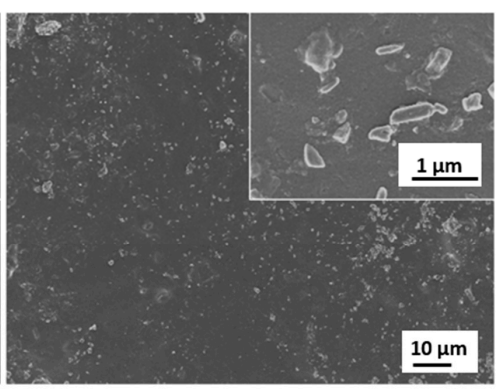

d)

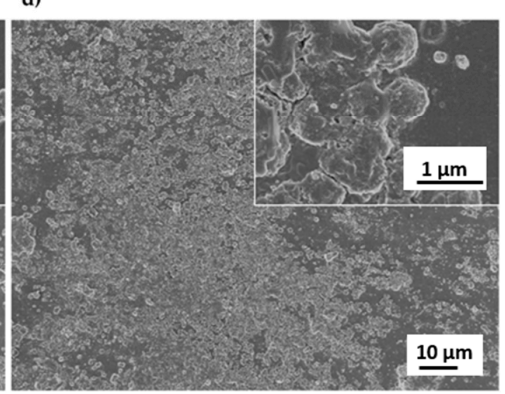

Figure 5. Representative SEM images of (a) TPS; (b) TPAS7; (c) TPAS14 and (d) TPAS21 films at lower $(1 \mathrm{KX})$ and higher $(100 \mathrm{KX})$ magnification.

\subsubsection{Thermal Stability}

Figure 6a shows the DSC curves of each film, evidencing the presence of the glass transition temperature and an endothermic peak. Several authors investigated the nature of the endothermic peak. 
Hanna et al. [33] attributed the endothermic peak to a residual gelation of the starch. Nevertheless, as shown in Figure 3, this observation is inconsistent with rheological findings, since the swelling process occurs at lower temperatures and it is independent from the presence of carbon ashes. Other authors [34,35] attributed the endothermic peak to both melting and thermal decomposition of the starch but this last hypothesis is not consistent with TGA results (Figure 6b), which, as will be discussed later, show a degradation temperature higher than that of the endothermic peak. Therefore, according to the authors in References $[34,35]$ the endothermic peak found in Figure 6a can be ascribed only to the melting of the starch crystals. The glass transition temperature $\left(T_{g}\right)$, the melting point $\left(T_{m}\right)$ and the melting enthalpy $\left(\Delta H_{m}\right)$ of each film were calculated from the curves of Figure 6a. In particular, the glass transition was calculated by identifying the point corresponding to the presence of an inflection and the melting enthalpy was calculated by normalizing the weight of each sample with the fraction of starch.

a)

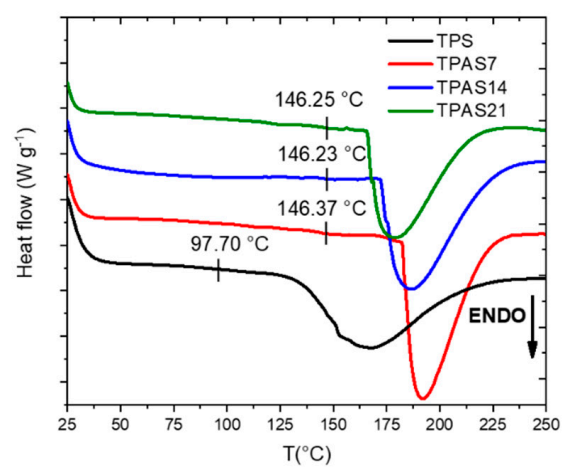

b)

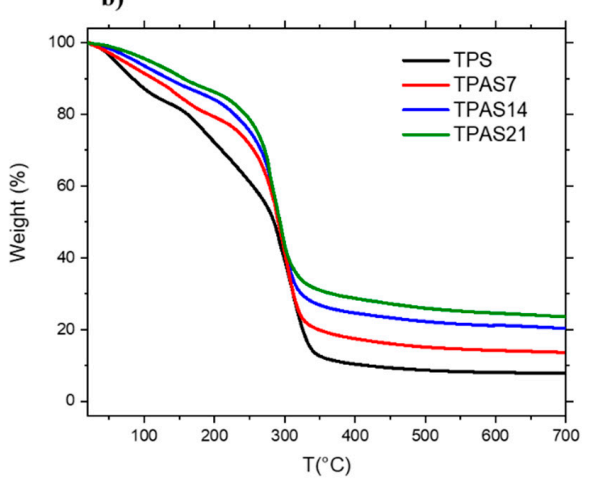

Figure 6. (a) Differential scanning calorimetry (DSC) and (b) TGA spectra of the thermoplastic recycled carbon ashes/starch (TPAS) films compared to that of the thermoplastic maize starch film.

Table 1 highlights a strong influence of carbon ashes on the $T_{g}$ of the system. In particular, the presence of the filler involves a change in the chain mobility of the starch amorphous phase, thus leading to an increase of the glassy region, with a $T_{g}$ shift of about $50{ }^{\circ} \mathrm{C}$, regardless the amount of the ashes.

Table 1. DSC and TGA values of thermoplastic starch (TPS) and thermoplastic recycled carbon ashes/maize starch (TPAS) films.

\begin{tabular}{cccccc}
\hline Sample & $\boldsymbol{T}_{\boldsymbol{g}}\left({ }^{\circ} \mathbf{C}\right)$ & $\boldsymbol{T}_{\text {PEAK }}\left({ }^{\circ} \mathbf{C}\right)$ & $\boldsymbol{\Delta} \boldsymbol{H}_{\boldsymbol{m}}\left(\mathbf{J} \cdot \mathbf{g}^{-\mathbf{1})}\right.$ & $\begin{array}{c}\text { Water Loss } \\
\mathbf{( \% )}\end{array}$ & Solid Residue (\%) \\
\hline TPS & 97.70 & 167.51 & $219.14 \pm 1.30$ & $14.96 \pm 1.87$ & $7.74 \pm 0.07$ \\
TPAS7 & 146.37 & 191.95 & $217.73 \pm 0.85$ & $12.03 \pm 0.86$ & $13.62 \pm 0.13$ \\
TPAS14 & 146.23 & 187.18 & $212.51 \pm 2.00$ & $11.54 \pm 0.61$ & $20.30 \pm 0.19$ \\
TPAS21 & 146.25 & 179.48 & $217.52 \pm 3.25$ & $9.30 \pm 0.53$ & $23.55 \pm 0.11$ \\
\hline
\end{tabular}

The presence of fillers involves a raise in glass transition temperature as the filler dispersion into the polymer chains causes a decrease in its mobility. The glass transition temperature of the polymer increases with increasing filler concentration and with increasing specific surface area of the filler. In addition, this increase is influenced by the distribution of the filler in the amorphous phase of polymer [36]; starting from these considerations, it should be expected that the glass transition temperature increases with increasing ashes content. On the other hand, high quantities of ashes are also leading to clusters formation (Figure 5), for these reasons comparable glass transition temperatures were recorded for every amount of filler.

The addition of carbon ashes also involves an alteration of the starch crystallization process. DSC curves of TPAS show indeed a shift in the melting peak temperature, principally due to an increase 
in crystallite size, rather than a modification of the overall crystallinity [37]. Specifically, Table 1 shows a decrease of the melting temperature as the ashes content is raised. This result is adducible again to the dispersion homogeneity of the filler, being sample TPAS7 the most uniform composite it alters the crystallization TPS process at most, (development of thicker crystals). The melting enthalpy of TPS, which is correlated to the crystalline fraction, instead, seems not to be strongly affected by the presence of the ashes; and only a slight decrease is detected in presence of ashes. The results are in agreement with the XRD data, where the use of carbon ashes was found not to considerably modify the crystalline fraction of the thermoplastic starch films and composites.

Thermogravimetric analyses were performed on all the sample produced, in order to evaluate the effect of the ashes on the starch thermal stability. The solid residue and the water weight loss are deduced from Figure $6 \mathrm{~b}$ and they are also reported in Table 1. All the samples show a first weight loss below $150{ }^{\circ} \mathrm{C}$, mainly attributed to the water evaporation and a second loss between $150{ }^{\circ} \mathrm{C}$ and $350{ }^{\circ} \mathrm{C}$, due to the contemporary evaporation of glycerol and the degradation of starch. In particular, when compared to TPS, the water content decreases by about $20 \%, 22 \%$ and $38 \%$ with a carbon ashes content of $7 \mathrm{wt} . \%, 14 \mathrm{wt} . \%$ and $21 \mathrm{wt} . \%$, respectively. As a such, the presence of ashes reduces the water absorption of the starch. Due to the overlap of the glycerol evaporation and starch degradation phenomena, taking place in the range of $150{ }^{\circ} \mathrm{C}$ and $350{ }^{\circ} \mathrm{C}$, no clear identification of the starch degradation temperature was possible. Therefore, since the evaporation of glycerol occurs up to $280^{\circ} \mathrm{C}$, a kinetic analysis was carried out in a range of temperature between $280^{\circ} \mathrm{C}$ and $320^{\circ} \mathrm{C}$, to study the difference in the degradation rate with and without ashes addition. The step ranging from $600^{\circ}$ to about $700{ }^{\circ} \mathrm{C}$, associated to the decomposition of $\mathrm{CaCO}_{3}$, in the carbon ashes curve (see Figure 2a) is not evident in the composites curves, maybe due to the sensibility of the instrument respect to the low $\mathrm{CaCO}_{3}$ concentration.

Figure 7 reports the results of the Broido analyses [28] applied to TPS and TPAS samples with different ashes contents. An insert in Figure 7 shows the activation energy $E_{a}$, calculated from the slope of each curve, with a linear fit of the data based on Equation8 (see material and methods). Against to TPS, the data show an increase of $30 \%, 20 \%$ and $10 \%$ in activation energy for the TPAS7, TPAS14 and TPAS21 samples, respectively, with the best result achieved for the lowest amount of carbon ashes added. The increase in activation energy is then an index of the higher thermal stability caused by presence of the ashes and their dispersion quality.

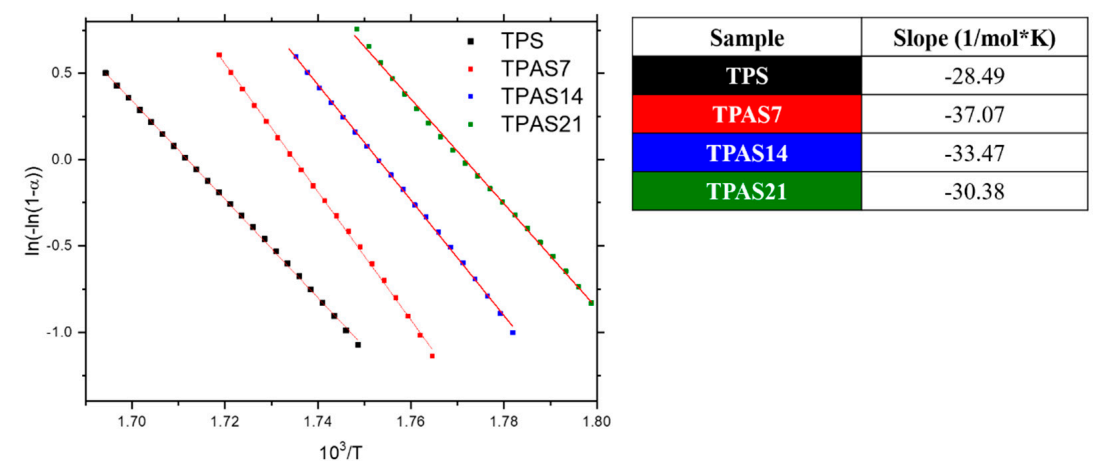

Figure 7. $\ln (-\ln (1-\alpha))$ vs. $1 /$ T plot using Broido method for the thermoplastic starch film (TPS) and thermoplastic recycled carbon ashes/starch films (TPAS) with different ashes contents.

The moisture absorption capacity of the thermoplastic films was assessed in extreme conditions of humidity ( $75 \%$ u.r.) (see materials and methods). Figure 8 a shows the average mass calculated from three samples for each composition and the respective standard deviation as a function of the time, while Figure $8 \mathrm{~b}$ reports the imbibition coefficient, $c_{i m}$, calculated by Equation (2) and the rate of absorption, calculated from the slope, $m_{s}$, of the initial portion of the curves for each film. The imbibition coefficient of the TPS film decreases from $23.75 \%$ to $13.29 \%$ (i.e., $44 \%$ ), from $23.75 \%$ to $16.73 \%$ (i.e., $30 \%$ ) and from $23.75 \%$ to $19.90 \%$ (i.e., $16 \%$ ) when $7 \mathrm{wt} . \%, 14 \mathrm{wt} . \%$ and $21 \mathrm{wt} . \%$ of 
ashes are added, respectively. The rate of absorption also is $0.068,0.025,0.030$ and $0.061 \mathrm{~g} / \mathrm{h}$ for TPS, TPAS7, TPAS14 and TPAS21 films, respectively. Therefore, the TPAS7 not only absorbs less water than TPS, TPAS14 and TPAS21 but it does it more slowly. This latter behavior could be attributed to the homogenous distribution of the carbon ashes into the polymeric matrix. The ashes, in fact, do not contribute to the water absorption of the starch film and, above all, they probably create a "network" among the starch molecules, similar to a tortuous path towards the water molecules, hindering, thus the swelling, due to the water absorption.

a)

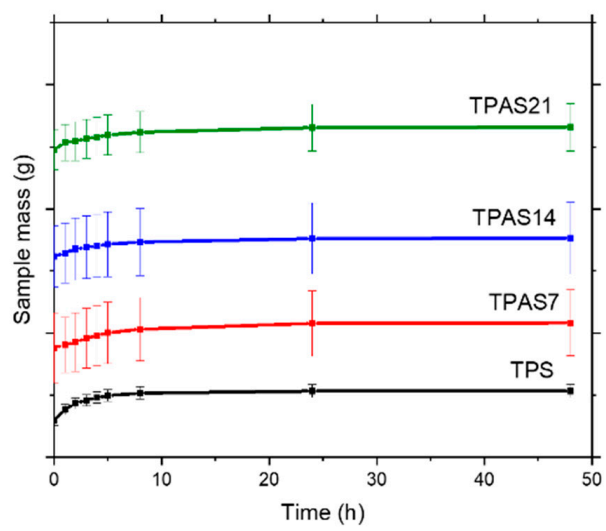

b)

\begin{tabular}{|c|c|c|}
\hline Sample & $\boldsymbol{c}_{\boldsymbol{i m}}(\mathbf{\%})$ & $\boldsymbol{m}_{\boldsymbol{s}}\left(\mathrm{g} \mathrm{h}^{-\mathbf{1}}\right)$ \\
\hline TPS & 23.75 & 0.068 \\
\hline TPAS7 & 13.29 & 0.025 \\
\hline TPAS14 & 16.73 & 0.030 \\
\hline TPAS21 & 19.90 & 0.061 \\
\hline
\end{tabular}

Figure 8. (a) Moisture absorption; (b) imbibition coefficient and rate of absorption of the thermoplastic starch (TPS) and thermoplastic recycled carbon ashes/starch (TPAS) films.

The biodegradability of the produced films was also investigated, in order to assess the influence of carbon ashes on the hydrophilicity of the starch. The weight loss was calculated and normalized by considering only the starch amount present in every sample. As shown on the left in Figure 9, for all samples a sharp weight loss occurs in the first $48 \mathrm{~h}$, followed by a lower degradation rate for longer times. The dissolution rate was then evaluated by the linear fit of the slope for each curve in the first $48 \mathrm{~h}$ of test, zooming the curve from 0 to $70 \mathrm{~h}$ (see insert on the right in Figure 9). The table in Figure 9 also reports the slope values of each curve. The presence of ashes was found to strongly decrease the deterioration of starch, independently of the filler amount; as shown in Figure 9, an average reduction of $70 \%$ in the dissolution rate was reached with the addition of carbon ashes.

a)

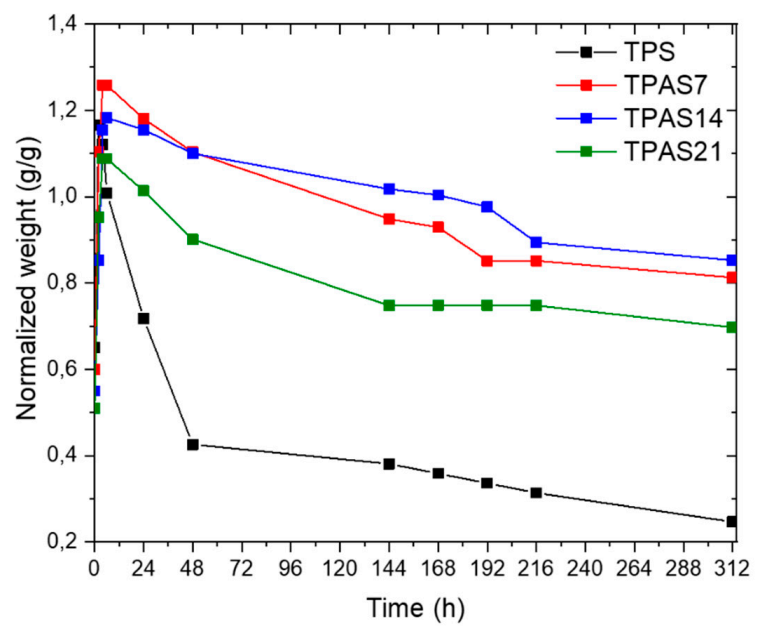

b)

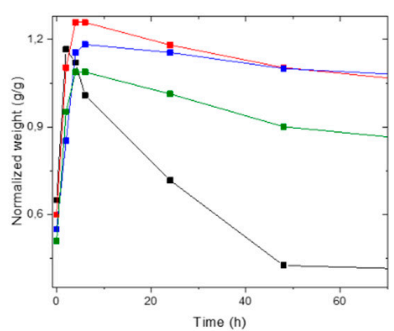

c)

\begin{tabular}{|c|c|}
\hline Sample & Slope $(\mathbf{1} / \mathbf{h})$ \\
\hline TPS & $-1.21 \mathrm{E}-2$ \\
\hline TPAS7 & $-3.90 \mathrm{E}-3$ \\
\hline TPAS14 & $-2.20 \mathrm{E}-3$ \\
\hline TPAS21 & $-3.20 \mathrm{E}-3$ \\
\hline
\end{tabular}

Figure 9. (a) Degradation curves of the thermoplastic starch (TPS) and thermoplastic recycled carbon ashes/starch (TPAS) films in terms of weight as a function of time; (b) zoom of the degradation curves from 0 to $70 \mathrm{~h}$; (c) slope values of each degradation curve. 


\subsubsection{Mechanical Analysis}

The effect of carbon ashes on TPS mechanical response was investigated through tensile tests, according to ASTM D882-97 [29]. In particular, based on results shown above, the addition of $7 \mathrm{wt} . \%$ of carbon ashes involved better results in terms of filler distribution and thermal stability. Therefore, tensile tests were performed only on TPAS7 films and compared with TPS samples.

The results, reported in Figure 10, show a slight stiffening effect of the filler, with an increase of about $20 \%$ in tensile modulus. On the other hand, the addition of carbon ashes involved a decrease of both tensile strength and elongation at break (Table 2), due to the increase in defects caused by the addition of the filler. In fact, though an amount of $7 \mathrm{wt} . \%$ of carbon ashes was found to ensure a better distribution (Figure 5), the presence of clusters and imperfections cannot be excluded. In this sense better mechanical properties can be reached by improving ashes distribution.

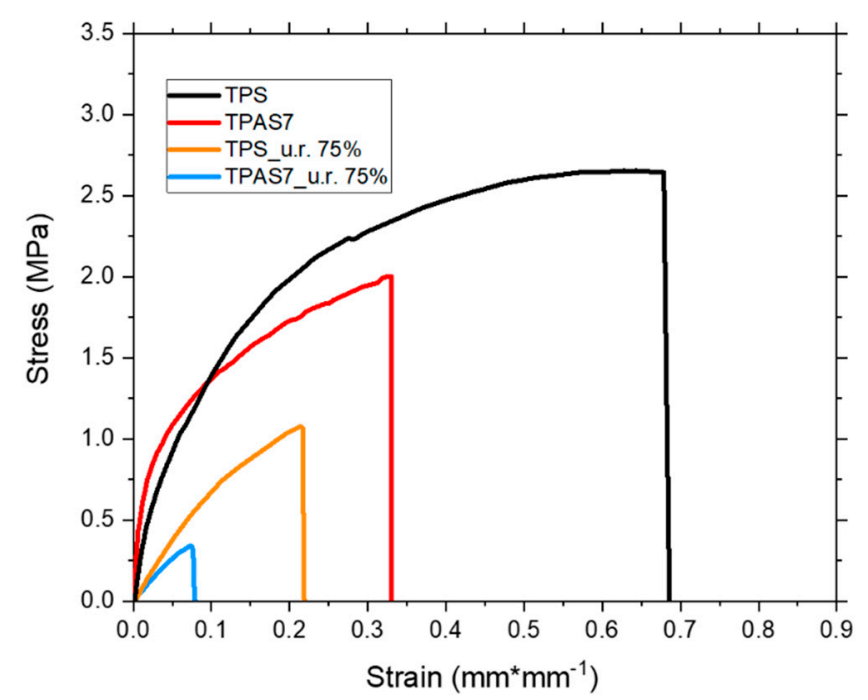

Figure 10. Stress-strain curve of the thermoplastic recycled carbon ashes/starch sample with an amount of $7 \mathrm{wt} . \%$ of ashes (TPAS7) in comparison to that of the thermoplastic starch film (TPS), before and after the weathering tests.

Table 2. Mechanical properties of the thermoplastic starch film (TPS) and thermoplastic recycled carbon ashes/starch film with an amount of $7 \mathrm{wt} . \%$ of ashes (TPAS7) before and after weathering tests.

\begin{tabular}{cccc}
\hline Sample & $\sigma_{f}(\mathbf{M P a})$ & $\varepsilon_{\boldsymbol{u}}\left(\mathbf{m m}^{*} \mathbf{m m}^{-\mathbf{1}}\right)$ & $\boldsymbol{E} \mathbf{( M P a )}$ \\
\hline TPS & $2.65 \pm 0.03$ & $0.66 \pm 0.05$ & $27.87 \pm 0.91$ \\
TPS_u.r. 75\% & $1.08 \pm 0.04$ & $0.23 \pm 0.01$ & $8.07 \pm 0.51$ \\
TPAS7 & $2.27 \pm 0.16$ & $0.33 \pm 0.03$ & $32.19 \pm 0.66$ \\
TPAS7_u.r. 75\% & $0.52 \pm 0.10$ & $0.07 \pm 0.02$ & $5.86 \pm 0.49$ \\
\hline
\end{tabular}

The moisture ageing caused, in any case, a reduction of the tensile modulus of the samples, since the increased water content acted as plasticizer for both TPS and TPAS7 films, after the weathering tests (samples named TPS_u.r. 75\% and TPAS7_u.r. 75\%, respectively). On the other hand, a decay in mechanical response was detected, with a sharp decrease of tensile strength and deformation at break for all the tested samples; this result can be attributable to a partial dissolution of the starch after the water exposure during moisture ageing.

\section{Conclusions}

In this work, an innovative approach for the recycling of carbon waste ashes by producing bio-composite thermoplastic starch films for agricultural applications was proposed. 
Several TPAS films were prepared by hand pre-mixing neat maize starch powder and $35 \mathrm{wt} . \%$ glycerol in presence of different amounts of waste carbon ashes ranging from $7 \mathrm{wt} . \%$ to $21 \mathrm{wt} . \%$. The compounds were mixed at $130{ }^{\circ} \mathrm{C}$ for $10 \mathrm{~min}$ and then compression molded. The effect of the different amounts of carbon ashes on the thermal and physical-mechanical properties of TPAS samples was assessed by using several techniques.

The XRD diffraction of all films produced showed that the presence of the carbon ashes does not influence the crystal planes of the starch. Moreover, the crystallinity of starch seems not to be directly affected by the presence of the filler. The SEM analysis indicated a good dispersion of the ashes for TPAS7 and a higher inhomogeneity in the distribution of the filler, besides the presence of carbon ashes clusters, for TPAS14 and, especially for TPAS21.

The DSC studies of each film evidenced the presence of an endothermic inflection point, related to the glass transition temperature and an endothermic peak, which can be ascribed to the melting of the starch crystals. The presence of the filler determined a $T_{g}$ shift of about $50{ }^{\circ} \mathrm{C}$, independently from the amount of the ashes. Furthermore, the increase in melting temperature in presence of ashes was ascribed to a change in the crystallization process, with a consequent increase in the crystallite dimension. On the other hand, the melting enthalpy of TPS seemed not to be strongly affected by the presence of the ashes.

The TGA analysis showed a reduction of the water absorption in presence of the starch, with a decrease in water content of about $20 \%, 22 \%$ and $38 \%$ with a carbon ash amount of $7 \mathrm{wt} . \%, 14 \mathrm{wt} . \%$ and $21 \mathrm{wt} . \%$, respectively. These results were confirmed by the moisture absorption tests which indicated that the imbibition coefficient of the TPS film decreases by about $44 \%, 30 \%$ and $16 \%$ when $7 \mathrm{wt} . \%$, $14 \mathrm{wt} . \%$ and $21 \mathrm{wt} . \%$ of ashes are added.

A kinetic analysis was carried out on a selected range of temperature (from 280 to $320^{\circ} \mathrm{C}$ ), where only degradation of the starch occurs, to study the difference in the degradation rate with and without ashes addition. Compared to TPS, the activation energy increases of $30 \%, 20 \%$ and $10 \%$ for TPAS7, TPAS14 and TPAS21, respectively. This increase in activation energy is an index of a higher thermal stability caused by the addition of the ashes.

The presence of ashes also decreases of $70 \%$ the deterioration of the starch, independently of the filler amount.

Finally, the tensile tests showed a slight stiffening effect of the filler, with an increase of about $20 \%$ in tensile modulus, for the TPAS7 film.

Author Contributions: Conceptualization, C.E.C.; methodology, C.E.C., F.F. and A.G.; software, E.S.; validation, C.E.C., F.F. and A.G.; formal analysis, C.E.C., F.F. and A.G.; investigation, E.S., V.A., F.F., A.G.; resources, C.E.C., E.F.; data curation, F.F. and A.G.; writing—original draft preparation, E.S., F.F., A.G.; writing-review and editing, C.E.C., E.F., S.C., A.L., A.R.; visualization, E.S., V.A., F.F., A.G.; supervision, C.E.C., E.F., S.C., A.L., A.R.; project administration, C.E.C. and E.F.; funding acquisition, C.E.C. and E.F. All authors have read and agreed to the published version of the manuscript.

Funding: The National Operational Program for Research and Innovation 2014-2020 (CCI 2014IT16M2OP005) of the Ministry of Education, University and Research founded this project.

Acknowledgments: The authors acknowledge the Ministry of Education, University and Research for the financial support, Costruzioni Motori Diesel (CMD) for supplying the carbon ashes and Donato Cannoletta for WAXD measurements.

Conflicts of Interest: The authors declare no conflict of interest.

\section{References}

1. Vassilev, S.; Baxtera, D.; Andersen, L.K.; Vassileva, C.G. An overview of the composition and application of biomass ash: Part 2. Potential utilisation, technological and ecological advantages and challenges. Fuel 2013, 105, 19-39. [CrossRef]

2. Justin Koh, J.; Zhang, X.; He, C. Fully biodegradable Poly(lactic acid)/Starch blends: A review of toughening strategies. Int. J. Biol. Macromol. 2018, 109, 99-113. 
3. Greco, A.; Ferrari, F.; Maffezzoli, A. Thermal analysis of poly(lactic acid) plasticized by cardanol derivates. J. Therm. Anal. 2018, 134, 559-565. [CrossRef]

4. Greco, A.; Ferrari, F.; Maffezzoli, A. Mechanical properties of poly(lactic acid) plasticized by cardanol derivates. Polym. Degrad. Sased Biopolym. Nat. Fibres Tab. 2018, 159, 199-204.

5. Dos Santos Rosa, D.; Lenz, D.M. Biocomposites: Influence of matrix nature and additives on the properties and biodegradation behaviour. In Biodegradation-Engineering and Technology; Chamy, R., Rosenkranz, F., Eds.; IntechOpen: London, UK, 2013.

6. Garkhail, S.K.; Meurs, E.; Van De Beld, T.; Peijs, T. Thermoplastic Composites Based on Biopolymers and Natural Fibres. Available online: fdocuments.in/document/thermoplastic-composites-based-onbiopolymers-and-natural-fibres.html (accessed on 14 February 2017).

7. Khalil, H.P.S.A.; Chong, E.W.N.; Owolabi, F.A.T.; Asniza, M.; Tye, Y.Y.; Rizal, S.; Nurul Fazita, M.R.; Haafiz, M.M.K.; Nurmiati, Z.; Paridah, M.T. Enhancement of basic properties of polysaccharide-based composites with organic and inorganic fillers: A review. J. Appl. Polym. Sci. 2019, 136, 47251. [CrossRef]

8. Pareta, R.; Edirisinghe, M.J. A novel method for the preparation of starch films and coatings. Carbohydr. Polym. 2006, 63, 425-431. [CrossRef]

9. Rosseto, M.; Krein, D.D.C.; Balbé, N.P.; Dettmer, A. Starch-gelatin film as an alternative to the use of plastics in agriculture: A review. J. Sci. Food Agric. 2019. [CrossRef]

10. Otey, F.H.; Mark, A.M.; Mehltretter, C.L.; Russell, C.R. Starch-based film for degradable agricultural mulch. Ind. Eng. Chem. Prod. Res. Dev. 1974, 13, 90-92. [CrossRef]

11. Otey, F.H.; Westhoff, R.P.; Doane, W.M. Starch-based blown films. Ind. Eng. Chem. Prod. Res. Dev. 1980, 19, 592-595. [CrossRef]

12. Otey, F.H.; Westhoff, R.P.; Doane, W.M. Starch-based blown films. 2. Ind. Eng. Chem. Res. Dev. 1987, 26, 1659-1663. [CrossRef]

13. Sun, T.; Li, G.; Ning, T.Y.; Zhang, Z.M.; Mi, Q.H.; Lal, R. Suitability of mulching with biodegradable film to moderate soil temperature and moisture and to increase photosynthesis and yield in peanut. Agric. Water Manag. 2018, 208, 214-223. [CrossRef]

14. Bilck, A.P.; Grossmann, M.V.E.; Yamashita, F. Biodegradable mulch films for strawberry production. Polym. Test. 2010, 29, 471-476. [CrossRef]

15. Dang, X.; Shan, Z.; Chen, H. The preparation and applications of one biodegradable liquid film mulching by oxidized corn starch-gelatin composite. Biotechnol. Appl. Biochem. 2016, 180, 917-929. [CrossRef]

16. Merino, D.; Gutiéerrez, T.J.; Alvarez, V.A. Structural and thermal properties of agricultural mulch films based on native and oxidized corn starch nanocomposites. Starch-Stärke 2019, 71, 1800341. [CrossRef]

17. Benito-González, I.; López-Rubio, A.; Martínez-Sanz, M. High-performance starch biocomposites with cellulose from waste biomass: Film properties and retrogradation behaviour. Carbohydr. Polym. 2019, 216, 180-188. [CrossRef] [PubMed]

18. Ibrahim, M.I.J.; Sapuan, S.M.; Zainudin, E.S.; Zuhri, M.Y.M. Potential of using multiscale corn husk fiber as reinforcing filler in cornstarch-based biocomposites. Int. J. Biol. Macromol. 2019, 139, 596-604. [CrossRef] [PubMed]

19. Collazo-Bigliardi, S.; Ortega-Toro, R.; Chiralt, A. Improving properties of thermoplastic starch films by incorporating active extracts and cellulose fibres isolated from rice or coffee husk. Food Packag. Shelf Life 2019, 22, 100383. [CrossRef]

20. Sreekumar, P.A.; Haque, S.K.M.; Afzal, H.M.; Sadique, Z.; Al-Harthi, M.A. Preparation and characterization of microcellulose reinforced polyvinyl alcohol/starch biocomposites. J. Compos. Mater. 2019, 53, 1933-1939. [CrossRef]

21. Torres, F.G.; Mayorga, J.P.; Vilca, C.; Arroyo, J.; Castro, P.; Rodriguez, L. Preparation and characterization of a novel starch-chestnut husk biocomposite. SN Appl. Sci. 2019, 1, 1158. [CrossRef]

22. Stasi, E.; Giuri, A.; La Villetta, M.; Cirillo, D.; Guerra, G.; Maffezzoli, A.; Ferraris, E.; Esposito Corcione, C. Catalytic activity of oxidized carbon waste ashes for the crosslinking of epoxy resins. Polymers 2019, 11, 1011. [CrossRef]

23. Stasi, E.; Giuri, A.; La Villetta, M.; Cirillo, D.; Guerra, G.; Maffezzoli, A.; Ferraris, E.; Esposito Corcione, C. Development and characterization of innovative carbon-based waste ashes/epoxy composites. Mater. Today Proc. 2020. manuscript accepted. [CrossRef] 
24. Hermans, P.H.; Weidinger, A. On the determination of the crystalline fraction of polyethylenes from X-ray diffraction. Macromol. Chem. Phys. 2003, 44, 24-36. [CrossRef]

25. Mano, J.F.; Koniarova, D.; Reis, R.L. Thermal properties of thermoplastic starch/synthetic polymer blends with potential biomedical applicability. J. Mater. Sci. Mater. Med. 2003, 14, 127-135. [CrossRef] [PubMed]

26. Hatakeyama, T.; Quinn, F.X. Thermal analysis: Fundamentals and Applications to Polymer Science. J. Am. Chem. Soc. 1996, 118, 5334 .

27. Soliman, A.A.A.; El-Shinnawy, N.A.; Mobarak, F. Thermal behaviour of starch and oxidized starch. Thermoch. Acta 1997, 296, 149-153. [CrossRef]

28. Broido, A. A simple, sensitive graphical method of treating thermogravimetric analysis data. J. Polym. Sci. $A-2$ 1968, 7, 1761. [CrossRef]

29. ASTM D882-97: Standard Test Method for Tensile Properties of Thin Plastic Sheeting. Available online: mahshahr.aut.ac.ir/lib/exe/fetch.php?media=labs:astm_d882.pdf (accessed on 8 June 2019).

30. Giuri, A.; Collella, S.; Listorti, A.; Rizzo, A.; Esposito Corcione, C. Biodegradable extruded thermoplastic maize starch for outdoor applications. J. Therm. Anal. 2018, 134, 549-558. [CrossRef]

31. Greco, A.; Ferrari, F.; Del Sole, R.; Maffezzoli, A. Use of cardanol derivatives as plasticizers for PVC. J. Vinyl Addit. Technol. 2016. [CrossRef]

32. Van Soest, J.J.G.; Hulleman, S.H.D.; de Wit, D.; Vliegenthart, J.F.G. Crystallinity in starch bioplastics. Ind. Crops Prod. 1996, 5, 11-22. [CrossRef]

33. Hanna, A.A.; Basta, A.H.; El-Saied, H.; Abadir, I.F. Thermal properties of cellulose acetate and its complexes with some transition metals. Die Angewandte Makromolekulare Chemie 1998, 260, 1-4. [CrossRef]

34. Kweon, D.K.; Cha, D.S.; Park, H.J.; Lim, S.T. Starch-g-polycaprolactone copolymerization using diisocyanate intermediates and thermal characteristics of the copolymers. J. Appl. Polym. Sci. 2000, 78, 986-993. [CrossRef]

35. Pichaiyut, S.; Nakason, C.; Wisunthorn, S. Biodegradability and thermal properties of novel natural rubber/linear low density polyethylene/thermoplastic starch ternary blends. J. Polym. Environ. 2018, 26, 2855-2866. [CrossRef]

36. Esposito Corcione, C.; Maffezzoli, A. Glass transition in thermosetting clay-nanocomposite polyurethanes. Therm. Acta 2009, 485, 43-48. [CrossRef]

37. Ferrari, F.; Greco, A. Thermal analysis of self-healing thermoplastic matrix nanocomposite from cyclic butylene terephthalate. J. Therm. Anal. 2018, 134, 567-574. [CrossRef] 